\title{
Establishment of the first World Health Organization International Standard for human parvovirus B19 DNA nucleic acid amplification techniques
}

\author{
J. Saldanha ${ }^{1}$, N. Lelie ${ }^{2}$, M. W. Yu ${ }^{3}$, A. Heath ${ }^{4}$ \&t the B19 Collaborative Study Group* \\ ${ }^{1}$ Division of Virology, National Institute for Biological Standards and Controls, South Mimms, Herts., UK \\ ${ }^{2}$ CLB, Plesmanlaan 125, Amsterdam, the Netherlands \\ ${ }^{3}$ Division of Hematology, CBER/FDA, Bethesda, Maryland, USA \\ ${ }^{4}$ Informatics Division, National Institute for Biological Standards and Controls, South Mimms, Herts., UK
}

\section{Vox Sanguinis}

Background and Objectives A collaborative study, involving 26 laboratories from 14 countries, was carried out in order to establish a World Health Organization (WHO) International Standard for human parvovirus B19 (B19) DNA nucleic acid amplification techniques (NAT).

Materials and methods Four samples: AA, BB (which were lyophilized), CC and DD (which were liquid preparations) were analysed using several different NAT assays. The mean B19 DNA content of each sample was determined for each laboratory using an end-point dilution method.

Results There was good agreement between the overall mean 'equivalents'/ml obtained by the different assays. The mean $\log _{10}$ 'equivalents' $/ \mathrm{ml}$ were 5.76 for sample AA, 5.73 for sample BB, 5.82 for sample CC and $7 \cdot 70$ for sample DD. The differences in titre among samples AA, BB and CC were not statistically significant, but the titre of DD was significantly higher.

Conclusions Despite the range of NAT assays used in the study, it was possible to calculate the mean B19 DNA concentrations in the four preparations. Lyophilized preparation AA was established as the first International Standard for B19 DNA NAT

Received: 19 June 2001, revised 29 August 2001, accepted 8 September 2001 assays and was assigned a concentration of $10^{6}$ international units (IU) $/ \mathrm{ml}$.

Key words: human parvovirus B19, International Standard, NAT assays, WHO collaborative study.

\footnotetext{
Correspondence: J. Saldanha, Division of Virology, National Institute for Biological Standards and Controls, Blanche Lane, South Mimms, Herts. EN6 30 , UK E-mail: jsaldanha@nibsc.ac.uk

*Dr J. Albrecht, National Genetics Institute, Los Angeles, CA, USA; Dr S. Buhr/Professor W. Roth, Blood Donor Service Hesse, Frankfurt, Germany; C. Chaput, NIBSC, South Mimms, Herts., UK; Dr Chudy/l. Schmidt, Paul Ehrlich Institut, Langen, Germany; Dr B. Cohen, Central Public Health Laboratory, London, UK; $\operatorname{Dr}$ C. Defer/Dr C. Lefebvre, Laboratoire de Biologie Moleculaire des Virus CRTS, Lille, France; Dr S. Doyle/Dr P. Daly, National University of Ireland, Maynooth, Ireland; Dr J. Echevarria, Instituto de Salud Carlos III, Madrid, Spain; Dr D. Erdman/Dr B. Anderson, Center for Disease Control, Atlanta, GA, USA; R. Fang/D. Johnstone, CSL Bioplasma, Broadmeadows, Australia; Dr T. Gierman, Bayer Corporation, Raleigh, USA; Dr P. Gross, Baxter/Immuno AG, Vienna, Austria; Dr I. Held, BIFA, Vienna, Austria; Dr L. Jarvis/A. Cleland, SNBTS/PCR Unit, Royal (Dick) Veterinary College, Edinburgh, UK; Dr A. Lazo/Dr V. Gibaja, Vitex, Boston, MA, USA; Dr T. Murozuka, Japanese Red Cross Fractionation Center, Chitose, Japan; Dr Y. Okada, National Institute of Infectious Diseases, Tokyo, Japan; Dr L. Pedada/Dr A. Lou, Alpha Therapeutics Corporation, City of Industry, CA, USA; Dr Pisani/Dr Gentili, Istituto Superiore di Sanita, Rome, Italy; Dr Saldanha, NIBSC, South Mimms, Herts., UK; Dr M. Stolz, Blutspendedienst SRK, Berne, Switzerland; Dr I. Thomas/Dr E. Mathy, Scientific Institute of Public Health, Brussels, Belgium; Dr T. Weimer, Aventis Behring, Marburg, Germany; Dr M.-Y. Yu/Dr L. M. Shen/B. Mason, CBER, Bethesda, MD, USA; Dr D. York, University of Natal, Congella, South Africa; Dr H. Zhang, National Institute for the Control of Pharmaceutical and Biological Products, Beijing, China.
} 


\section{Introduction}

Human parvovirus B19 (B19) causes erythema infectiosum (EI), transient aplastic crisis in patients with haemolytic anaemia (TAC), and has been associated with fetal death, arthritis and chronic anaemia [1]. B19 is a common infection in humans and most people become infected during their lifetime $(\approx 40-60 \%$ of adults over 20 years of age have antibodies to B19) [2]. The majority of plasma pools used to prepare blood products have been shown to be contaminated with B19 sequences [3,4]. B19 is non-enveloped and thermostable and therefore difficult to inactivate by the standard inactivation methods (solvent-detergent, pasteurization) that are used during the manufacture of blood products. Recent studies have shown that B19 DNA sequences are present in a range of blood products [5,6]. Although B19 is normally spread via the respiratory route, parenteral transmission can occur through the administration of blood products made from plasma pools contaminated with B19 [7-9]. Despite the presence of antibodies to B19 in all plasma pools, some products made from contaminated pools have been recently reported [9] to transmit B19 as a result of the high viral load.

Reducing the levels of B19 by screening plasma minipools for B19 DNA may be necessary in order to minimize the potential risk of transmission and improve the margin of safety of products used to treat, for example, immunocompromised individuals, haemophiliacs and pregnant women. Diagnosis of B19 is based on the detection of specific immunoglobulin M (IgM) or immunoglobulin G (IgG) antibodies [2,10], nucleic acid hybridization assays [11], or, more recently, nucleic acid amplification technology (NAT) assays [12]. The most sensitive assay for detecting B19 in plasma pools, where the virus may be present in low concentrations, is NAT. However, NAT assays vary widely in sensitivity and specificity and the use of a well-calibrated standard is essential for comparison of data and the routine introduction of such assays. A working reagent for B19 NAT assays has been available since 1997 [13] but there is a need for an International Standard that can be used to calibrate secondary standards and to validate and calibrate assays.

The first World Health Organization (WHO) International Standard for NAT assays was established in 1997 for hepatitis C virus (HCV) RNA assays [14] and was essential for the introduction of routine screening of blood donations and plasma pools for HCV RNA by NAT assays. In 1999, two further WHO International Standards for hepatitis B virus (HBV) DNA and human immunodeficiency virus-1 (HIV-1) RNA assays were established $[15,16]$. The objectives of the present study were to assess the suitability of candidate preparations as the WHO International Standard for B19 DNA for use in NAT assays and to determine the B19 DNA content of the candidate standard.

\section{Materials and methods}

\section{Participants}

Results were returned by 26 laboratories (reference laboratories, blood product manufacturers, kit manufacturers, regulatory laboratories and research laboratories) from 14 different countries. Each laboratory was allocated a random code number.

\section{Preparation and evaluation of candidate materials}

Four candidate materials were included in the study: samples AA and BB were lyophilized preparations and samples CC and DD were liquid preparations. Materials $\mathrm{AA}$ and $\mathrm{BB}$ were prepared by diluting a positive donation, containing $\approx 2 \times 10^{12}$ genome equivalents $/ \mathrm{ml}$ (geq $/ \mathrm{ml}$ ), $10^{6}$-fold in 2.51 of pooled plasma. Sample CC (B19 DNA concentration $\approx 10^{6} \mathrm{geq} / \mathrm{ml}$ ) was prepared by the Center of Biologics Evaluation and Research (CBER) (Bethesda, MD) by diluting a positive donation in pooled plasma. Sample DD (B19 DNA concentration $\approx 10^{7}-10^{8}$ geq/ $\mathrm{ml}$ ) was prepared at the Central Laboratory of the Netherlands Blood Transfusion Service (CLB) (Amsterdam, the Netherlands) by diluting a positive donation in pooled plasma. All diluents were negative for HBV DNA, B19 DNA, HCV RNA and HIV RNA, and negative for antibodies to B19, hepatitis B surface antigen (HBsAg), HCV and HIV, except the diluent used to prepare AA and BB which was positive for antibodies to B19.

\section{Lyophilization of samples AA and BB}

Lyophilization of the material was performed as previously described for the HCV [14] and HBV [15] candidate International Standards. The coefficient of variation of the fill volume was $0 \cdot 63 \%$ and $0 \cdot 71 \%$ for samples $\mathrm{AA}$ and $\mathrm{BB}$, respectively.

\section{Design of the study}

Participants were sent four vials of each material and requested to perform four independent assays (for B19 DNA) of the four samples on different days. For each assay, dilutions of all four candidate materials (prepared in the sample diluent normally used in the assay system) were to be tested concurrently so that the B19 DNA content of each preparation could be determined. The first assay of the four candidate materials was performed using 10-fold dilutions of the preparations in order to determine the B19 DNA end-point of each preparation, while the remaining three assays were carried out on half-log dilutions (i.e. $1: 3 \cdot 3$ dilutions) on either side of the determined end-points.

\section{Statistical methods}

The statistical methods used for this study were identical to those used in previous collaborative studies to establish 
International Standards for HCV RNA [14] and HBV DNA [15]. The relative potencies were calculated as the differences in estimated $\log _{10}$ polymerase chain reaction (PCR) detectable units $/ \mathrm{ml}$, and the statistical significance of differences between samples was assessed using paired $t$-tests.

Qualitative assays were analysed as previously described $[14,15]$. Briefly, for each laboratory and assay method, data from all assays were pooled to give the number positive out of the number tested at each dilution step. A single 'end-point' for each such dilution series was calculated by the method of maximum likelihood, using the statistical package GLIM [17]. The calculated end-point was used to give an estimated number of 'detectable units $/ \mathrm{ml}$ ' after correcting for the equivalent volume of the test sample. The estimates, referred to as 'PCR detectable units $/ \mathrm{ml}$ ', are not necessarily directly equivalent to a genuine copy number $/ \mathrm{ml}$ or genome equivalent $/ \mathrm{ml}$.

Duplicate test results, where reported in an assay, were treated as if from independent assays.

For quantitative assays, a single estimate was obtained for each sample (by calculating the mean of repeat estimates within a single assay after correcting for sample dilution), and estimates for all assays were used to calculate overall mean estimates for individual laboratories.

\section{Accelerated degradation studies on sample AA}

Vials of sample AA were incubated at $+4^{\circ} \mathrm{C},+20^{\circ} \mathrm{C},+37^{\circ} \mathrm{C}$ and $+45^{\circ} \mathrm{C}$, and duplicate vials were removed, as shown in Table 1 , and stored at $-20^{\circ} \mathrm{C}$ until analysis. For comparison, vials stored at $-20^{\circ} \mathrm{C}$ were extracted and amplified in parallel. For analysis, the vials were thawed and the contents redissolved in $0.5 \mathrm{ml}$ of DNAse-free water for $20 \mathrm{~min}$ at room temperature. It was not possible to redissolve the contents of vials incubated at $+45^{\circ} \mathrm{C}$ for 3 weeks or longer.

B19 DNA was extracted from $200 \mu \mathrm{l}$ of samples using the Qiagen DNA mini kit (Qiagen, Hilden, Germany). Briefly, the samples were dissolved in a proteinase K/guanidinium buffer, the nucleic acids bound to a silica filter, washed to remove contaminants and eluted in $60 \mu \mathrm{l}$ of water. For PCR analysis, $10 \mu \mathrm{l}$ of sample was amplified in a LightCycler (Roche Molecular Biochemicals, Mannheim, Germany).

Table 1 Calculated mean titres $\left(\log _{10} \mathrm{IU} / \mathrm{ml}\right)$ of the samples in the accelerated degradation study compared with the titre of the candidate standard AA (stored at $-20^{\circ} \mathrm{C}$ )

\begin{tabular}{llllll}
\hline & \multicolumn{4}{l}{ Incubation temperature } \\
\cline { 2 - 6 } Incubation time & $\mathbf{- 2 0}{ }^{\circ} \mathrm{C}$ & $\mathbf{+ 4}{ }^{\circ} \mathbf{C}$ & $\mathbf{+ 2 0}{ }^{\circ} \mathbf{C}$ & $\mathbf{+ 3 7}^{\circ} \mathbf{C}$ & $\mathbf{+ 4 5}^{\circ} \mathbf{C}$ \\
\hline 1 week & $6 \cdot 0$ & & & $5 \cdot 9$ & $5 \cdot 9$ \\
4 weeks & $6 \cdot 0$ & $6 \cdot 1$ & $5 \cdot 9$ & $6 \cdot 1$ & - \\
8 weeks & $6 \cdot 0$ & & & $6 \cdot 1$ & - \\
\hline
\end{tabular}

\section{PCR amplification}

$\log _{10}$ dilutions of the samples were prepared in diluent $(10 \mathrm{ng} / \mathrm{ml}$ tRNA in water) and amplified using the Roche LightCycler system. The samples were amplified in two batches. For each batch of samples, duplicate vials of AA, stored at $-20^{\circ} \mathrm{C}$, were amplified in parallel. In order to calculate the titres, a standard curve was constructed for each experiment. For the standard curve, $\log _{10}$ dilutions of the two samples stored at $-20{ }^{\circ} \mathrm{C}$ were prepared and amplified. The titre of the undiluted material was taken as $10^{6} \mathrm{IU} / \mathrm{ml}$. For the test samples, $10^{-1}$ and $10^{-2}$ dilutions were assayed.

\section{Results}

\section{Assays}

All laboratories returned data from qualitative assays. Laboratory 8 returned data from two different assay methods, and the results are reported separately (8A and $8 \mathrm{~B})$. Laboratories 16 and 18 used two different extraction methods, and the results are reported separately (16A, 16B, 18A and 18B). Two laboratories ( 2 and 19) returned data from quantitative assays in addition to their qualitative results, while laboratory 12 provided qualitative and quantitative data from the same set of assays. All the quantitative assays were based on TaqMan real-time PCR using the ABI Prism 7700 (Applied Biosystems, Foster City, CA) and the results are reported separately $(02 Q, 12 Q$ and $19 Q)$. The overall results are therefore based on a maximum of 32 data sets ('laboratories'). All laboratories used in-house PCR assays, with a single primer pair or nested primers from the NS1, VP1 or VP2 regions. Laboratory 8 used a commercial assay (8B; SMI Test, Genome Science Laboratory Co. Ltd, Japan).

For B19 DNA extraction, the majority of laboratories used common commercial extraction kits such as the QIAamp viral RNA and DNA blood or mini kits (Qiagen) and the Nuclisens kit (both manual and automated) (Organon Teknika, Boxtel, the Netherlands). Other commercial kits used were the Roche/Boehringer High Pure Template preparation kit (Penzberg, Germany) (laboratory 1), the Watson kit (laboratory 10) and the SMI test (Genome Science Laboratory Co. Ltd) (laboratories 8 and 26). Several laboratories used proteinase $\mathrm{K} /$ sodium dodecyl sulphate (SDS) digestion followed by phenol-chloroform extraction or heat inactivation, while two laboratories, 14 and 21, used sodium iodide extraction and laboratory 17 used $\mathrm{NaOH}$ extraction followed by neutralization with $\mathrm{HCl}$. Laboratories 9 and 18 used a chaotropic agent followed by absorption onto silica.

\section{Estimates of PCR detectable units $/ \mathrm{ml}$ or geq $/ \mathrm{ml}$}

The estimates of PCR detectable units/ml obtained from the 
Fig. 1 Laboratory estimates of $\log _{10}$ polymerase chain reaction (PCR) detectable units or genome equivalents/ml for: (a) sample $A A$; (b) sample $B B$; (c) sample CC; and (d) sample DD.

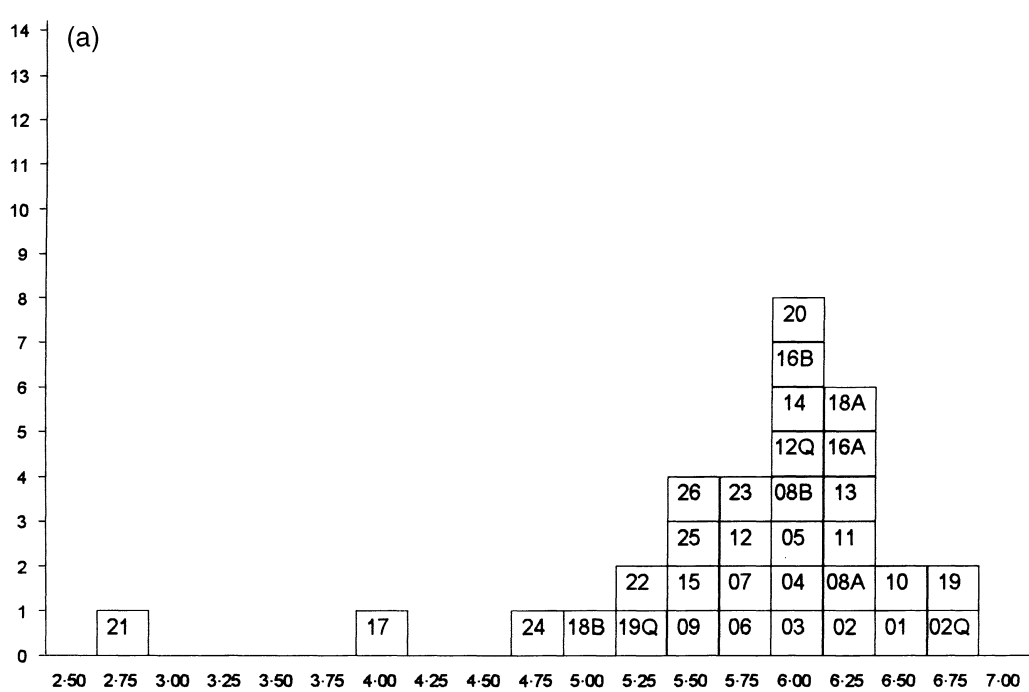

$\log _{10}$ PCR detectable units or genome equivalents $/ \mathrm{ml}$

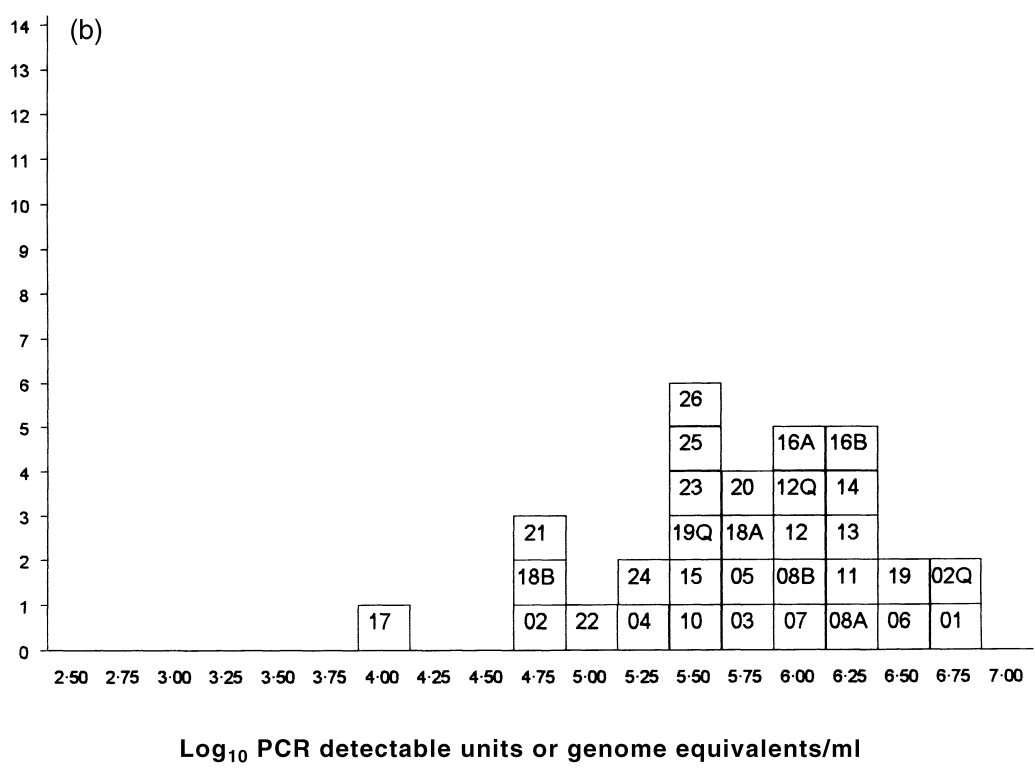

qualitative assays, and the estimates of geq $/ \mathrm{ml}$ obtained from the quantitative assays, are shown in histogram form in Fig. 1(a-d) for samples AA to DD, respectively. Each box represents the estimate from one laboratory and/or method and is labelled with the laboratory code number. In some cases, it was not possible to calculate results using the Poisson model owing to inconsistent results for a particular dilution series (sample BB, laboratory 9) or because of dilution errors, which resulted in all samples in a dilution series being positive or negative (sample DD, laboratories 21 and 23).

The majority of laboratories had estimates that were within a range of $2 \cdot 0 \log _{10}$ for each sample. However, results from some laboratories (laboratory 21, samples AA and DD; and laboratory 17 , samples $\mathrm{AA}$ and $\mathrm{BB}$ ) were lower than the majority of results. The overall means for each sample are given in Table 2, along with the standard deviation and range of estimates between laboratories. For laboratories that followed the recommended layout for the qualitative assays, 95\% confidence intervals for an individual laboratory estimate were $\approx 0.5 \log _{10}-0.8 \log _{10}$ PCR detectable units $/ \mathrm{ml}$ in overall width. This reflects the degree of uncertainty inherent in any laboratory estimate and should be borne in mind when comparing results between laboratories. The shape of the distribution of estimates for sample CC and, to a lesser extent, sample DD, appeared bimodal, with a group of laboratories obtaining similar estimates that were lower than those of the majority of laboratories. It is not clear whether this could be the result of the different assay methods having different 

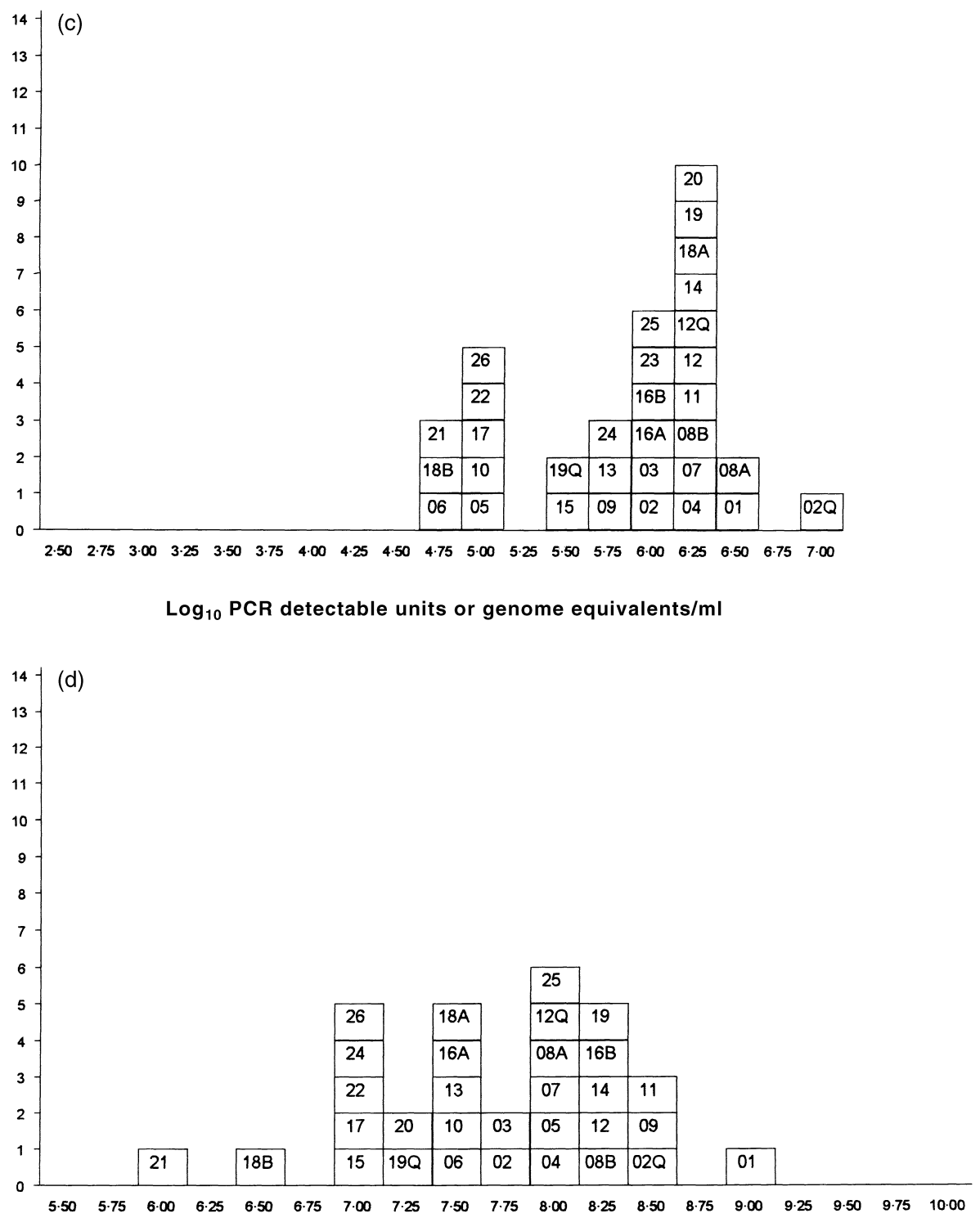

$\log _{10}$ PCR detectable units or genome equivalents $/ \mathrm{mI}$

Fig. 1 Continued

sensitivities to sample CC, or whether it was simply a result of individual assay variability.

\section{Relative potencies}

The potencies of samples BB, CC and DD obtained for each laboratory were expressed relative to sample AA and are shown in Fig. 2(a-c), respectively. The overall means, along with standard deviations and ranges, are given in Table 3. However, the variation between laboratories has only been reduced slightly, reflecting the considerable assay variability inherent in the qualitative assays used in this study. The shape of the distribution of relative potencies for sample CC (Fig. 2b) does not exhibit the bimodal shape noted above for the distribution of direct estimates of 'units'/ml (Fig. 1c), suggesting that there is not a different sensitivity to sample CC between assay methods.

\section{Accelerated degradation studies}

As duplicate samples were assayed at each time-point for each temperature, four sets of data were obtained for each time point/temperature, except for samples incubated for 4 weeks at $+4{ }^{\circ} \mathrm{C}$ and for 1 week at $+45^{\circ} \mathrm{C}$. The calculated mean concentrations (IU/ml) for each time-point/temperature are shown in Table 1 . The results indicated that AA was stable at $+4{ }^{\circ} \mathrm{C}$ and $+20^{\circ} \mathrm{C}$ for at least 4 weeks and at $+37^{\circ} \mathrm{C}$ for at least 8 weeks. The sample was also stable at $+45^{\circ} \mathrm{C}$ for 

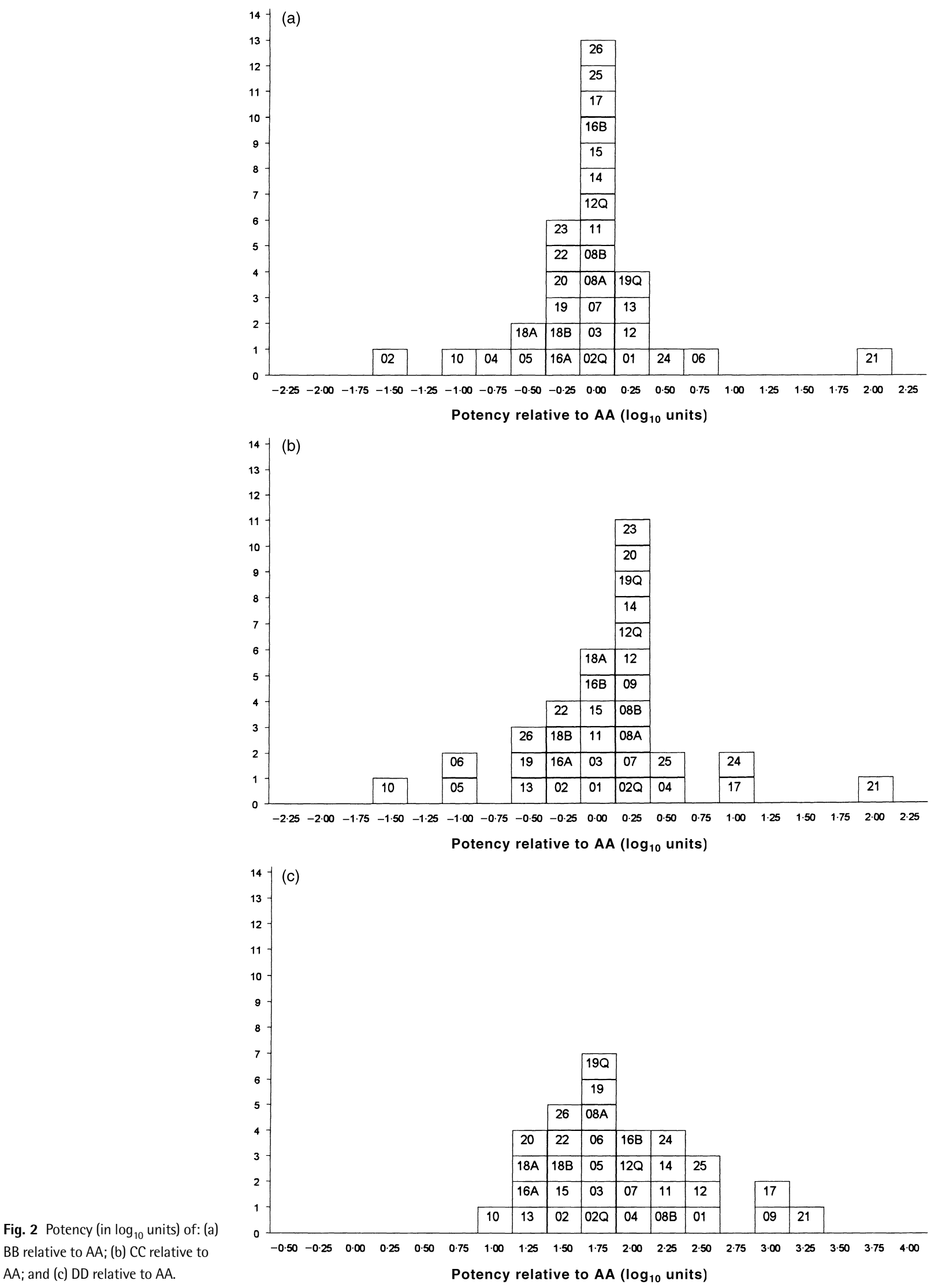
Table 2 Overall mean estimates $\left(\log _{10}\right.$ 'equivalents' $\left./ \mathrm{ml}\right)$ for the four candidate samples

\begin{tabular}{|c|c|c|c|c|c|}
\hline $\begin{array}{l}\text { Sample } \\
\text { (data set) }^{\mathrm{a}}\end{array}$ & Mean & $\begin{array}{l}\text { Standard } \\
\text { deviation }\end{array}$ & Minimum & Maximum & Range \\
\hline \multicolumn{6}{|l|}{ AA } \\
\hline 1 & $5 \cdot 76$ & 0.80 & $2 \cdot 73$ & $6 \cdot 72$ & 3.99 \\
\hline 2 & $5 \cdot 86$ & 0.58 & 3.92 & $6 \cdot 72$ & $2 \cdot 80$ \\
\hline 3 & 5.92 & 0.47 & 4.84 & $6 \cdot 72$ & $1 \cdot 88$ \\
\hline \multicolumn{6}{|l|}{ BB } \\
\hline 1 & $5 \cdot 73$ & 0.63 & 3.92 & $6 \cdot 85$ & 2.93 \\
\hline 2 & $5 \cdot 76$ & $0 \cdot 62$ & 3.92 & $6 \cdot 85$ & $2 \cdot 93$ \\
\hline 3 & $5 \cdot 82$ & 0.52 & $4 \cdot 78$ & $6 \cdot 85$ & 2.07 \\
\hline \multicolumn{6}{|l|}{$\mathrm{CC}$} \\
\hline 1 & $5 \cdot 82$ & 0.58 & $4 \cdot 69$ & 6.90 & $2 \cdot 21$ \\
\hline 2 & $5 \cdot 85$ & 0.55 & $4 \cdot 79$ & 6.90 & $2 \cdot 11$ \\
\hline 3 & 5.89 & 0.53 & $4 \cdot 79$ & 6.90 & $2 \cdot 11$ \\
\hline \multicolumn{6}{|l|}{ DD } \\
\hline 1 & $7 \cdot 70$ & 0.66 & $6 \cdot 10$ & $9 \cdot 08$ & 2.98 \\
\hline 2 & $7 \cdot 75$ & 0.60 & $6 \cdot 50$ & $9 \cdot 08$ & $2 \cdot 58$ \\
\hline 3 & $7 \cdot 78$ & 0.51 & $6 \cdot 50$ & $9 \cdot 08$ & $2 \cdot 58$ \\
\hline
\end{tabular}

aData sets: 1, all laboratories; 2 , excluding laboratory $21 ; 3$, excluding laboratories 17 and 21.

1 week, but analysis of material incubated at $+45^{\circ} \mathrm{C}$ for longer than 1 week was not possible owing to the insolubility of the material.

\section{Discussion}

The WHO has established clear guidelines for the development of International Standards. Two requirements are particularly important: International Standards should be stable, lyophilized materials; and laboratories from as many countries as possible should be allowed to participate in the developmental process. Clearly, some participating laboratories will not be as proficient as other laboratories. The aim of the study, however, is to determine whether the candidate material can be assayed by different assays in several laboratories and then to assign a potency to the material. While this should be as close to its concentration a possible, it is not the aim to obtain an accurate figure for the concentration of the material. The agreed standard will then be used by laboratories to validate and standardize their assay methods.

In this study there was good agreement between the overall mean 'detectable' units/ml obtained by all participants, except for laboratories 17 and 21. However, omitting results from these laboratories made little difference to the overall mean estimates for the four candidate samples (Table 2) and results from all laboratories were included for the final overall mean estimates. Sample AA (code 99/800) was accepted
Table 3 Overall mean potencies of samples BB, CC and DD relative to sample AA ( $\log _{10}$ 'units'/ml)

\begin{tabular}{lcllll}
\hline $\begin{array}{l}\text { Sample } \\
\text { (data set) }\end{array}$ & Mean & $\begin{array}{l}\text { Standard } \\
\text { deviation }\end{array}$ & Minimum & Maximum & Range \\
\hline BB & & & & & \\
1 & -0.04 & 0.55 & -1.41 & 2.01 & 3.42 \\
2 & -0.11 & 0.41 & -1.41 & 0.64 & 2.05 \\
3 & -0.11 & 0.42 & -1.41 & 0.64 & 2.05 \\
CC & & & & & \\
1 & 0.06 & 0.62 & -1.50 & 1.95 & 3.45 \\
2 & -0.00 & 0.52 & -1.50 & 1.00 & 2.50 \\
3 & -0.04 & 0.49 & -1.50 & 1.00 & 2.50 \\
DD & & & & & \\
1 & 1.94 & 0.55 & 0.88 & 3.37 & 2.49 \\
2 & 1.89 & 0.48 & 0.88 & 3.00 & 2.12 \\
3 & 1.85 & 0.44 & 0.88 & 2.91 & 2.03 \\
\hline
\end{tabular}

${ }^{a}$ Data sets: 1 , all laboratories; 2 , excluding laboratory $21 ; 3$, excluding laboratories 17 and 21 .

as the first WHO International Standard for human parvovirus B19 DNA NAT assays by the WHO Expert Committee on Biological Standardization (ECBS) at their meeting in November 2000. The proposed assigned potency of this material is $10^{6} \mathrm{IU} / \mathrm{ml}$ and each vial of the International Standard contains $5 \times 10^{5} \mathrm{IU}$. Using the calculated mean titres for sample AA (Table 2), the ratio of IU: PCR detectable units is $1: 0 \cdot 6-0 \cdot 8$. However, if the data from only the quantitative assays (2Q, 12Q and 19Q) are used, the ratio is 1: 2 (IU: genome equivalents).

Despite B19 infection being of short duration with mild clinical symptoms in the majority of cases, many blood product manufacturers have begun screening for B19 by NAT in plasma minipools [18]. Unlike HCV RNA screening of pools where all positive donations are removed from the manufacturing pool, B19 DNA screening is aimed at reducing the level of B19 DNA in the manufacturing pool and not eliminating all positive donations, as this would lead to unacceptably high losses of plasma. A common strategy is to test donations in minipools and remove all donations with titres $>10^{6}$ geq/ $\mathrm{ml}$ [18]. Removal of such donations results in manufacturing pools containing $<10^{4} \mathrm{geq} / \mathrm{ml}$. Preliminary results indicate that products made from screened pools are negative for B19 DNA. Data derived from studies with solvent-detergent treated pooled plasma [9] have suggested that B19 transmissions were associated with product lots having high levels of B19 DNA but not with those having $<10^{4} \mathrm{geq} / \mathrm{ml}$. At present, there are no mandatory requirements for B19 DNA screening. However, in the USA, the Blood Products Advisory Committee (BPAC) concluded at the 1999 BPAC meeting that NAT for B19 would be considered by the Food and Drug Administration (FDA) to be an 'in-process' control rather than a donor 
screening test. Consequently, blood product manufacturers would only be required to validate the assay in terms of sensitivity, specificity and reproducibility, and would not be required to perform clinical trials for assay validation. The proposed FDA limit for manufacturing pools, based on B19 transmission by solvent-detergent pooled plasma [19,20], is $<10^{4} \mathrm{geq} / \mathrm{ml}$. The use of B19 NAT as a limit test to control the amount of virus in plasma pools requires the availability of well-calibrated standards in order to define and measure these limits. The establishment of an International Standard for B19 NAT assays would provide such a reagent.

\section{References}

1 Anderson LJ: Human parvoviruses. J Infect Dis 1988; 161:603-608

2 Cohen BJ, Buckley MM: The prevalence of antibodies to human parvovirus B19 in England and Wales. J Med Microbiol 1998; 25:151-153

3 Saldanha J, Minor P: Detection of human parvovirus B19 in plasma pools and blood products derived from these pools: implications for efficiency and consistency of removal of B19 during manufacture. Br J Haematol 1996; 93:714-719

4 Willkommen H, Schmidt I, Löwer J: Safety issues for plasma derivatives and benefit from NAT testing. Biologicals 1999; 27:325-331

5 Lefrere JJ, Mariotti M, Thauvin M: B19 parvovirus DNA in solvent/detergent-treated anti-haemophilia concentrates. Lancet 1994; 343:211-212

6 Lefrere JJ, Mariotti M, De la Croix I, Lerable J, Thauvin M, Burnouf T, Follea G: Albumin batches and B19 parvovirus DNA. Transfusion 1995; 35:389-391

7 Morfıni M, Longo G, Rossi Ferrini P, Azzi A, Zakrewska C, Ciappi S, Kolumban P: Hypoplastic anaemia in a haemophiliac first infused with a solvent/detergent-treated factor VIII concentrate: the role of human B19 parvovirus. Am J Hematol 1992; 39:1490-1500

8 Hino M, Ishiko 0, Honda K-I, Yamane T, Ohta K, Takubo T, Tatsumi N: Transmission of symptomatic parvovirus B19 infection by fibrin sealant used during surgery. Br J Haematol 2000; 108:194-195

9 Davenport R, Geohas G, Cohen S, Beach K, Lazo A, Lucchesi K, Pehta J: Phase IV study of PLAS+ SD: hepatitis A (HAV) and parvovirus B19 safety results. Blood 2000; 96:451a
10 Anderson LJ, Tsou C, Parker RA, Chorba TL, Wulff H, Tattersall P, Mortimer PP: Detection of antibodies and antigens of human parvovirus B19 by enzyme-linked immunosorbent assay. J Clin Microbiol 1986; 24:522-526

11 Musiani M, Zerbini M, Gibellini D, Gentilomi S, Venturoli S, Gallinella G, Ferri E, Girotti S: Chemiluminescence dot-blot hybridisation for the detection of B19 parvovirus DNA in human sera. J Clin Microbiol 1991; 29:2047-2050

12 McOmish F, Yap PL, Jordan A, Hart H, Cohen BJ, Simmonds P: Detection of parvovirus B19 in donated blood: a model system for screening by polymerase chain reaction. $J$ Clin Microbiol 1993; 31:323-328

13 Saldanha J, Minor P, and the B19 Collaborative Study Group: Collaborative study to assess the suitability of a proposed working reagent for human parvovirus B19 DNA detection in plasma pools by gene amplification techniques. Vox Sang 1997; 73:207-211

14 Saldanha J, Lelie N, Heath A, and the WHO Collaborative Study Group: Establishment of the first International Standard for nucleic acid amplification technology (NAT) assays for HCV RNA. Vox Sang 1999; 76:149-158

15 Saldanha J, Gerlich W, Lelie N, Dawson P, Heermann K, Heath A and the WHO Collaborative Study Group: An international collaborative study to establish a World Health Organisation international standard for hepatitis B virus DNA nucleic acid amplification techniques. Vox Sang 2001; 80:63-71

16 Holmes H, Davis C, Heath A, Hewlett I, Lelie N: An international collaborative study to establish the first International standard for HIV-1 RNA for use in nucleic acid based assays. $J$ Virol Methods 2001; 92:141-150

17 Francis B, Green M, Payne C (eds): The GLIM System, Release 4 Manual. Oxford, Oxford Science Publications, Clarendon Press, 1993

18 Aubin JT, Defer C, Vidaud M, Maniez Montreuil M, Flan B: Large-scale screening for human parvovirus B19 DNA by PCR: application to the quality control of plasma for fractionation. Vox Sang 2000; 78:7-12

19 Tabor E, Yu M-Y, Hewlett I, Epstein JS: Summary of a workshop on the implementation of NAT to screen donors of blood and plasma for viruses. Transfusion 2000; 40:1273-1277

20 Brown KE, Young NS, Alving BM, Barbosa LH: Parvovirus B19: implications for transfusion medicine. Summary of a workshop. Transfusion 2001; 41:130-135 